\title{
Uptake and performance of farm-based measures for reducing crop raiding by elephants Loxodonta africana among smallholder farms in Laikipia District, Kenya
}

\author{
M.D. Graham and T. Ochieng
}

\begin{abstract}
Human-elephant conflict, in particular the damage caused by elephants to smallholder crops, is a major challenge to the conservation of African elephant Loxodonta africana. Conventional tools used to address this problem are capital intensive and require high levels of expertise. In recent years simple, affordable farm-based elephant deterrents, using locally available materials, have been encouraged by a number of human-elephant conflict researchers. There are very few published studies demonstrating the performance of these deterrents, however, and little is known about levels of uptake among smallholder farmers. We trialled a number of such farm-based elephant deterrents with local farmers in three sites within Laikipia District, Kenya. Levels of crop raiding declined after the introduction of treatments but not significantly when
\end{abstract}

compared with control farms. Variable levels of uptake among the participating farmers made it difficult to draw clear conclusions from the trials. However, participating farmers were positive about the deterrent effect of the tools introduced, corroborated by their willingness to make financial commitments towards sustaining future trials. Availability of household labour, local politics, and insecurity were identified as important barriers to uptake of some of the deterrents introduced. Household labour availability should be a key consideration in future endeavours to trial farm-based elephant deterrents.

Keywords African elephant, human-elephant conflict, Loxodonta africana, uptake, community-based, Kenya, Laikipia.

\section{Introduction}

Human-elephant conflict, in particular the problem of crop raiding, is arguably one of the defining challenges for the conservation of elephant Loxodonta africana populations in Africa (Thouless, 1994; Barnes, 1996; Hoare, 2000), with the exception of those elephant populations currently under intense hunting pressure from the ivory and bushmeat trades in Central Africa's equatorial forests (Blanc et al., 2003; Stephenson, 2004; Lee \& Graham, 2006).

Surprisingly, the conventional approach used to mitigate crop raiding by elephants has changed little since the colonial era: so-called problem elephants are shot and, where resources allow, barriers are constructed to separate elephants from cultivation (Hoare, 1995). While in some cases there is evidence to suggest that these mitigation tools can be effective (Thouless \& Sakwa,

M.D. Graham* (Corresponding author) and T. Ochieng Laikipia Elephant Project, Centre for Training and Research in ASAL Development, P.O. Box 144, Nanyuki, Kenya. E-mail mdg34@cam.ac.uk

*Also at: Department of Geography, University of Cambridge, Cambridge, CB2 3EN, UK.

Received 13 April 2007. Revision requested 2 July 2007.

Accepted 30 October 2007
1995; O'Connell-Rodwell et al., 2000; Osborn \& Parker, 2003; Omondi et al., 2004), they are often ineffective (Osborn, 1998; Hoare, 2001). In addition, many rural farmers living within elephant ranges are beyond the reach of such human-elephant conflict management services. For these reasons smallholder farmers are, in many cases, left with the responsibility of defending their own farms from elephants.

Within such contexts there is an emerging view among human-elephant conflict researchers that cropraiding mitigation efforts should focus on improving traditional farm-based elephant deterrent systems through the introduction and application of simple and affordable tools (Osborn \& Parker, 2003). There is some evidence to show that such an approach can reduce levels of crop raiding (Sitati \& Walpole, 2006), although there are few published studies of farm-based human-elephant conflict mitigation trials. Furthermore, there is little evidence to suggest that once introduced, such farm-based elephant deterrents will be taken up by farmers other than those participating in the trials.

We carried out trials of farm-based elephant deterrents among smallholder farmers in Laikipia District, Kenya, as part of a community outreach project, between 2004 and 2005. These trials were carried out by local farmers on a voluntary basis and therefore do not 
represent a set of strictly controlled random experiments, nor was this our aim. Rather our aim was to apply, demonstrate and evaluate community-based tools for human-elephant conflict management, with the consent and participation of local community groups. Here we share our results and experiences with a view to informing future efforts to implement and study community-based approaches for alleviating humanwildlife conflict.

\section{Study area}

Laikipia District $\left(9,700 \mathrm{~km}^{2}\right)$, in north-central Kenya, encompasses a plateau of rolling low hills at 1,700-2,000 m, straddling the equator, north-west of Mt Kenya (5,199 m) and north-east of the Aberdare Highlands (3,999 m). Laikipia is unusual in that it supports high densities of large mammals, including Kenya's second largest elephant population $(>5,000$ animals), but contains no formally protected wildlife areas. As a consequence, elephants in Laikipia move across a land-use mosaic comprised of large-scale private ranches, communally owned pastoral areas and smallholder farms (Thouless, 1995, 1996; Graham, 2007). Inevitably this has led to human-elephant conflict, in particular crop raiding, which occurs on cultivated smallholder farms in the wetter, southern part of the district. This conflict is intense; in one year alone a total of 3,668 human-elephant conflict incidents were recorded, of which 2,420 involved damage to crops (Graham, 2007).

Management of crop raiding by elephants in Laikipia has taken several forms. Elephants were shot in defence of crops in the 1920s (DC/LKA/1/115, 1928) and continue to be shot today in legal control by the wildlife authorities or illegally killed by local farmers. In 1978, at considerable expense, a large-scale elephant drive unsuccessfully attempted to push elephants out of the arable southern portion of Laikipia into the arid and semi-arid rangelands of Samburu and Isiolo Districts (Mwenge International Ltd, 1979). Subsequently, electrified fencing became the preferred human-elephant conflict management approach in Laikipia. In 1982 a district-wide elephant fence was proposed, to separate elephant tolerant from elephant intolerant areas (Jenkins \& Hamilton, 1982). Similar fencing solutions were proposed in 1993 (Thouless, 1993), 1998 (Wafula, 1998) and 2002 (Thouless et al., 2002). Private ranches in Laikipia have, where resources allow, adopted this strategy, so that today there exist a number of electrified fences separating ranches from smallholder farms. However constructing and maintaining such fences is expensive and as a consequence much of the human-elephant interface in Laikipia remains unfenced and/or porous to elephant movement, leaving smallholder farmers highly vulnerable to crop raiding.

\section{Methods}

\section{Human-elephant conflict enumeration}

Ten local enumerators systematically collected data on crop raiding and other forms of human-elephant interaction in Laikipia District between January 2002 and December 2005. Scouts were trained on data collection protocols, using an adapted version of IUCN's training package for enumerators of elephant damage (Hoare, 1999), as described by Sitati \& Walpole (2006).

\section{Farm-based crop-raiding deterrents}

Part way through the monitoring period, training and materials for farm-based elephant deterrents was provided free of charge to farmers in three different sites, at different stages, in response to project funding cycles. In the first site, Mutara, training and materials were provided to a group of farmers between June and December 2002 for the collective defence of a smallholder cultivated area measuring $0.03 \mathrm{~km}^{2}$. Another area, within $1 \mathrm{~km}$, and of equal size, was selected as a control. The deterrents, adapted from Osborn \& Parker (2002) were: (1) Chilli rope fences: Two-strand fences made of locally available sisal rope were erected around cultivated farms; squares of white mutton cloth were stretched between the two strands to create a highly conspicuous barrier; a mixture of ground dried chillies and engine grease was regularly applied to the rope and squares of mutton cloth. (2) Cow bells: Metal cow bells, manufactured in the local town, were hung from each chilli fence to act as an alarm if an elephant tried to break through the perimeter rope fence. (3) Chilli smoke briquettes: Farmers were trained on the production of chilli dung briquettes, made by mixing chillies with elephant dung and a little water in a mould and leaving to dry in the sun; these briquettes were then placed on fires on the perimeter of farms at night to generate a noxious chilli smoke. (4) Noise makers: Purchased bangers and locally manufactured 'banger sticks' (these are made using local materials and matchstick heads) were distributed to farmers within the trial areas. (5) Watchtowers and solar powered torches: Watchtowers (6-9 m high) were constructed on a farm located close to elephant refuges and the farmers that manned the watchtowers were provided with powerful solar-powered torches.

In the second phase of trials we used a different approach after experiencing difficulties with the collective defence of a farming area. Training and materials for farm-based deterrents were provided to individual farmers willing to participate in the trials. These deterrents were trialled with 10 farmers in $\mathrm{Ol}$ Moran in west Laikipia between February and November 2005, and 10 farmers in Salaama, near the Rumuruti Forest, south-west 
Laikipia, between April and November 2005. A comparative group of 10 farms, all within $2 \mathrm{~km}$ of trial farms, was selected in each site to provide a control.

\section{Questionnaire survey}

To evaluate uptake of the individual farm-based treatments and perceptions of their effectiveness, farmers involved in the trials were interviewed using a standard questionnaire in Mutara $(\mathrm{n}=10)$, Ol Moran $(\mathrm{n}=10)$ and Salaama $(n=10)$. For comparative purposes 10 owners of non-trial farms were also interviewed in each site, although results from three interviews within the control site in Mutara were incomplete and therefore discarded. The questionnaire included a mixture of open and fixed-response questions, covering the respondent's socio-economic background, cultivation patterns, availability of household labour, farm-based elephant deterrents used, elephant deterrents abandoned, reasons for not using/abandoning certain elephant deterrents, and perceptions of effectiveness.

\section{Data analysis}

Both temporal and spatial comparisons of crop raiding by elephants on trial and non-trial farms were carried out. There were two measures used to evaluate change in levels of crop raiding: (1) The number of crop-raiding events on trial and non-trial farms, before and after the provision of training and materials for deterring elephants, and (2) the average cultivated area damaged $\left(\mathrm{m}^{2}\right)$ on trial and non-trial farms, before and after the application of treatments. The farm was used as the sampling unit of measurement so that an individual foray by an elephant group may have involved more than one cropraiding incident. Some of the trial and control farms from Ol Moran and Salaama did not experience crop raiding prior to the application of treatments and therefore data from these farms were excluded prior to analysis. For each trial area comparisons were made between two equivalent periods before and after the application of treatments. Thus, for example, in the Mutara site, where training and materials were introduced between June and December 2004, comparisons were made with the period between June and December 2003.

Level of uptake of farm-based deterrents and perceptions of effectiveness are presented as response frequencies, using response categories either contained in the questionnaire survey or constructed on the basis of responses. Uptake was measured by calculating the proportion of trial farms that reported continued use of deterrents over the trial period after the initial provision of training and materials. All data were analysed using SPSS v. 12 (SPSS, Chicago, USA), using nonparametric tests for statistical comparisons.

\section{Results}

\section{Crop raiding on trial and non-trial farms}

There were 92 crop-raiding incidents within the treatment area in Mutara over the trial period compared with 26 incidents over the same period in 2003. The average cultivated area damaged per incident reduced from $585 \mathrm{~m}^{2}$ in 2003 to $375 \mathrm{~m}^{2}$ in 2004 . In contrast, the control area experienced a dramatic increase in the number of crop-raiding incidents between the two periods, from 17 over June-October 2003 to 166 incidents over the same period in 2004. The average cultivated area damaged per incident also increased within the control area, from $328 \mathrm{~m}^{2}$ in 2003 to $421 \mathrm{~m}^{2}$ in 2004 .

Eighteen of the 20 trial farms at $\mathrm{Ol}$ Moran and Salaama experienced crop raiding prior to the introduction of treatments. While crop raiding declined on 11 of the 18 farms, the overall impact of the deterrents varied and was not significant (median number of raids on trial farms: before treatments $=2$, interquartile range, $\mathrm{IQR}=4.5 ;$ after treatments $=2.5, \mathrm{IQR}=3$; Wilcoxon signed ranks test $\left.Z_{18,18}=-1.8, P=0.07\right)$. The average area damaged per incident also declined on trial farms, from $852.6 \mathrm{~m}^{2}$ prior to the application of treatments to $648 \mathrm{~m}^{2}$ afterwards. Eleven of the 20 control farms experienced crop raiding prior to the application of treatments. Surprisingly there was a significant decline in crop raiding recorded on 10 of these 11 control farms (median number of raids on control farms: before treatments $=3$, $\mathrm{IQR}=3$; after treatments $=1, \mathrm{IQR}=4$; Wilcoxon signed ranks test $Z_{11,11}=-2.3, P=0.02$ ) and average crop damage per incident declined from $405 \mathrm{~m}^{2}$ to $366 \mathrm{~m}^{2}$.

\section{Uptake of crop-raiding deterrents}

Uptake varied both among the different deterrents provided and between the three sites (Table 1). The chilli smoke briquette was the most successful treatment in terms of uptake among the trial farms, followed by the banger stick. The banger stick might have been used more if it had not been banned during the monitoring period by the provincial administration over fears that it could be misused in an area where armed theft is common. Less than half of the farmers provided with training and materials for the construction and maintenance of chilli fences continued to use this deterrent, with many complaining of the labour required to maintain the fences and regularly reapply the chilli-grease mixture to the individual sisal strings and squares of mutton cloth. Trial farms on which chilli fences were abandoned had a significantly lower number of night guards than farms that used chilli fences (median number of guards on trial farms that used chilli fences $=2$, range $1-5$, $\mathrm{n}=23$; median number of guards on trial farms that 
Table 1 Uptake of individual crop-raiding deterrents among trial farms in three human-elephant conflict sites in Laikipia District (Fig. 1).

\begin{tabular}{|c|c|c|c|c|c|}
\hline \multirow[b]{2}{*}{ Deterrent } & \multicolumn{4}{|c|}{ Uptake rate $\%$ (abandoned \%) } & \multirow[b]{2}{*}{ Application benefits/barriers } \\
\hline & Mutara & Ol Moran & Salaama & All sites & \\
\hline Chilli fence & $11(89) \mathrm{n}=9$ & $33(67) \mathrm{n}=9$ & $80(20) n=10$ & $46(54) n=26$ & $\begin{array}{l}\text { Labour intensive, expensive, requires regular } \\
\text { reapplication of chilli grease }\end{array}$ \\
\hline Cow bell & $0(100) \mathrm{n}=8$ & $11(89) \mathrm{n}=9$ & $70(30) n=10$ & $33(67) \mathrm{n}=24$ & Stolen by pastoralists, ineffective as an alarm \\
\hline Chilli dung & $80(20) n=10$ & $100(0) n=10$ & $100(0) \mathrm{n}=9$ & $93(7) \mathrm{n}=29$ & Low cost, low labour requirements, effective \\
\hline $\begin{array}{l}\text { Watchtower \& } \\
\text { torch }\end{array}$ & $40(60) \mathrm{n}=5$ & $0(0) \mathrm{n}=0$ & $50(50) \mathrm{n}=6$ & $45(55) n=11$ & $\begin{array}{l}\text { Expensive, problems with sharing among } \\
\text { farmers, difficult to climb (requires young } \\
\text { labour), effective }\end{array}$ \\
\hline Banger sticks & $62.5(37.5) \mathrm{n}=8$ & $87.5(12.5) \mathrm{n}=8$ & $57(43) \mathrm{n}=7$ & $69(31) n=23$ & Low cost, effective, banned by the police \\
\hline
\end{tabular}

abandoned chilli fences $=1$, range $1-2, \mathrm{n}=7$; MannWhitney $U$ test $=40.5, \mathrm{P}<0.05$, two-tailed).

Only 11 farmers from trial farms had direct access to watchtowers and solar-powered torches; due to funding constraints only three watchtowers were constructed, one in each of the three study sites. Six of these farmers abandoned using the watchtower altogether, complaining that the farmer on whose farm the watchtower was built would not share the torch and/or that the watch- tower was too difficult to climb and required younger labour. The torches provided were also frequently damaged by the participating farmers and often were not repaired or replaced for 1 week or more. The cow-bell early warning deterrent had the lowest uptake rate. The majority of farmers reported abandoning the cow bells because they were either stolen, or were at risk of being stolen, by pastoralists. A number of farmers also reported that the bells were ineffective as an alarm.

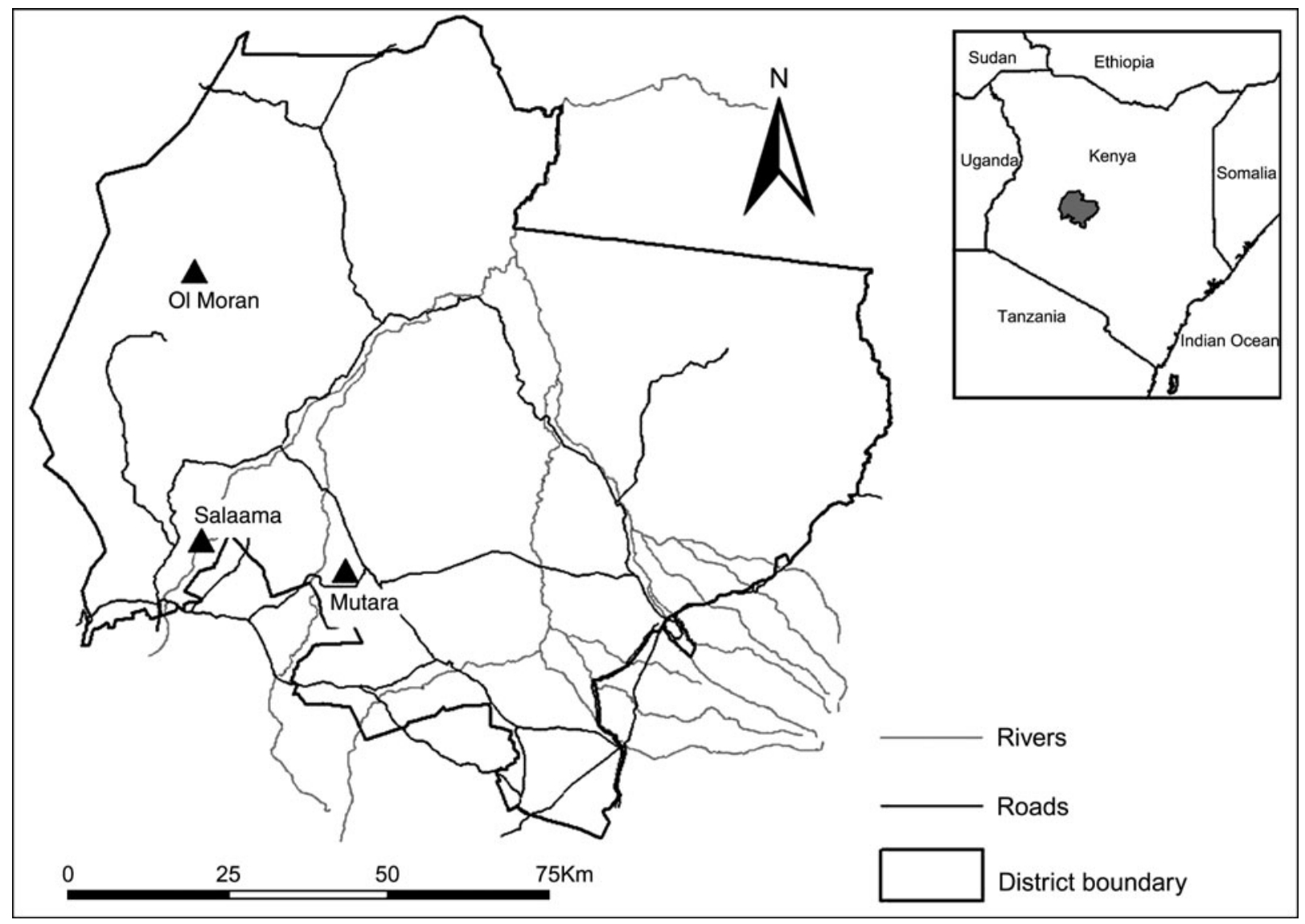

Fig. 1 Laikipia District in north-central Kenya, showing the three locations where human-elephant conflict mitigation trials were carried out. The inset indicates the location of Laikipia in Kenya. 
During the trial a small proportion of control farms in each site took up farm-based deterrents introduced to the trial farms. Seven farmers from the control farms reported using the dung briquette. Two farmers from the control farms erected chilli fences of their own accord, one of whom also procured and used a cow bell, and three farmers from the control farms either constructed their own watchtowers or helped man the watchtowers constructed on trial farms.

\section{Local perceptions of effectiveness}

Sixty-five percent of the respondents from the trial farms reported that the treatments helped to protect their crops $(n=29)$. The balance of respondents claimed that the elephant deterrents helped a little but did not solve the problem. None of the participating farmers reported that the deterrents did not help at all. Respondents from trial farms were willing to contribute financially towards the cost of materials with a view to sustaining the deterrents introduced (median financial contribution offered $=\mathrm{KES}$ $500, \mathrm{IQR}=1,000, \mathrm{n}=30$; KES $68=\mathrm{USD} 1$ ). In contrast, respondents from control farms offered significantly less money towards purchasing materials for farm-based elephant deterrents (median financial contribution offered $=$ KES 50, IQR $=1,000, \mathrm{n}=27 ;$ Mann-Whitney $U_{30,27}=280, \mathrm{P}<0.05$, one-tailed).

\section{Discussion}

In contrast to the success reported by Sitati \& Walpole (2006) the farm-based deterrents introduced in this study did not significantly deter crop-raiding elephants. Declines in crop raiding recorded on trial farms may have simply reflected a background decline in crop raiding, as indicated by the simultaneous decline recorded on control farms. However, drawing clear conclusions from these results is problematic for a number of reasons. The variable uptake of farm-based treatments among trial farms and the unexpected uptake of treatments among control farms may have compromised our results. Whereas the emergence of these factors as confounding variables may have undermined the scientific rigour of the trials, they also represent an important finding that could have been overlooked had we used a more controlled experimental design.

Sitati \& Walpole (2006) argued that even the successful demonstration of farm-based deterrents would not guarantee uptake by farmers. In our study labour constraints were identified by participating farmers as a barrier to the uptake and maintenance of farm-based deterrents. Household labour availability has been identified as a key factor in determining vulnerability to crop depredation in other parts of Africa (Naughton-Treves,
1997; Hill, 2004). Labour requirements for the protection of crops are often reported as an indirect cost associated with human-wildlife conflict, creating labour bottlenecks in certain seasons (Hill, 2004), greater exposure to diseases such as malaria (Hill, 2000; Naughton-Treves, 2001) or disruption to education because children are needed to guard fields at night (Tchamba, 1996; Sitati, 2003; Hill, 2004).

In Transmara District chilli fences required the application of chilli grease on a weekly basis (Sitati \& Walpole, 2006). We requested that participating farmers in Laikipia also carry this not inconsiderable labour burden and it is perhaps unsurprising that such a large proportion of the participating farmers abandoned this deterrent. Labour constraints may also explain why the watchtowers were not widely used. In contrast, low labour requirements are likely to explain the extremely high uptake of the chilli dung briquette and, to a lesser extent, the banger stick.

Other factors also affected uptake in our study. For example several participating farmers abandoned farmbased treatments at Mutara, possibly in response to a rumour spread by a local politician that participation in the trial would compromise the ability of Mutara farmers to receive support for the construction of an electrified fence. In addition, insecurity, a consequence of the availability of absentee land to nomadic pastoralists (Graham, 2007), led to a large proportion of farmers abandoning the cow bells provided.

Despite the influence of confounding variables in evaluating the deterrent effect of the treatments, results from the trial conducted at Mutara merit further discussion. The trial area was located closer to the boundary of ADC Mutara Ranch, the source of crop-raiding elephants, than the control area (Fig. 2). Distance to daytime elephant refuges, such as national parks, forests and, in Laikipia, large private ranches, increases vulnerability to crop raiding (Bell, 1984; Newmark et al., 1994; Naughton-Treves, 1998; Graham, 2007) and therefore the trial area in Mutara is arguably more vulnerable to crop raiding than the control area, possibly reflected in the pattern of crop raiding prior to the application of treatments. The lower level of crop-raiding increase recorded in the trial area over the trial period, relative to the dramatic increase recorded in the control area, could, therefore, have been the result of the elephant deterrents introduced, effectively displacing crop-raiding elephants into the control area. A similar pattern of displacement was identified in the trials carried out by Sitati \& Walpole (2006) and among farms adjacent to an electrified fence in Tsavo National Park, where conflict increased towards each end of the fence (Smith \& Kasiki, 1999). This pattern of crop-raiding change recorded in the Mutara site, combined with the perspective that the 


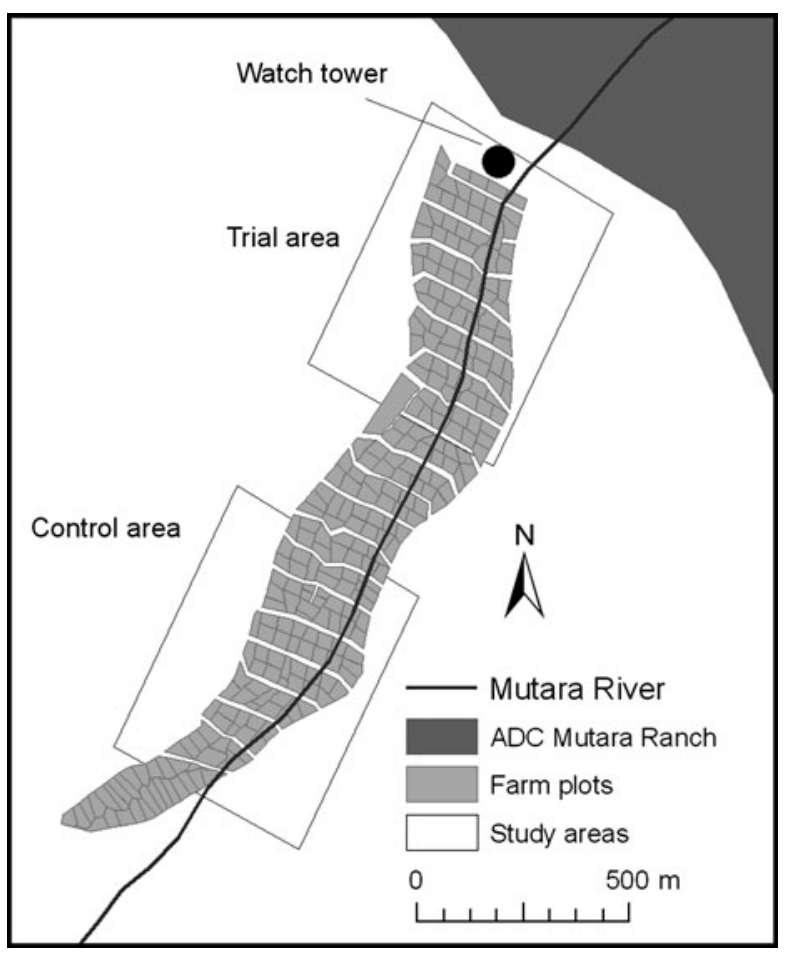

Fig. 2 The Mutara site, showing the location of the trial area and control area relative to the location of the neighbouring ranch, which is the source of crop-raiding elephants.

treatments introduced had a deterrent effect, held by the majority of participating farmers, merits further trials of farm-based deterrents, despite the methodological challenges.

This study used an experimental design, adapted from Sitati \& Walpole (2006), using time series comparisons between treatment and control farms before and after the treatments took place. While this experimental design may be an improvement on treatment-response trials and/or post-treatment spatial comparisons between trial and control farms ( $\mathrm{O}^{\prime}$ Connell-Rodwell et al., 2000; Osborn \& Parker, 2002), the trials were still carried out within an uncontrolled environment and relied on the willingness and ability of local farmers to participate. As a consequence we were not able to select the sample of farms to work with at random, complicating our experimental design. Future efforts to quantify the impact of farm-based deterrents should control for potential biases in uptake by ensuring that adequate labour is committed to each of the participating farms. In addition, and in contrast to Sitati \& Walpole (2006), we combined all crop-raiding deterrents in our trials. There would be merit in further studies of individual deterrents.

Human-elephant conflict in Laikipia is severe, undermining conservation efforts and ultimately threatening the future of elephants in the wider ecosystem. The social challenges we experienced with implementing farm-based elephant deterrents suggest that this approach is unlikely to eradicate the problem and instead should be used to complement, rather than replace, existing management approaches. Currently funding has been secured for a district-wide elephant fence in Laikipia (Thouless et al., 2002). Where this fence abuts well funded private conservancies that can afford to cover recurrent maintenance and enforcement costs, then previous research suggests that it is likely to reduce crop raiding by elephants substantially (Thouless \& Sakwa, 1995). However if responsibility for the maintenance of sections of the fence is to be delegated to local communities then the same factors that undermined the implementation of farm-based deterrents in this study, namely labour constraints and local politics, are also likely to undermine fence effectiveness in the long-term. It is critical, therefore, that the elephant-tolerant side of the fence in Laikipia is sufficiently committed and resourced to absorb long-term maintenance costs. This may necessitate the creation of conservancies (private, government and/or community) where none currently exist, a distinct possibility in Laikipia where substantial private conservation resources are available, which is unusual compared with many other African elephant ranges.

\section{Acknowledgements}

The authors are grateful to Bill Adams, Matt Walpole, Chris Thouless and Tim Jackson for their comments on this manuscript. This research was undertaken with the kind permission of the President of the Republic of Kenya by the Symbiosis Trust through grants provided by Safaricom Ltd and The Elephant Pepper Trust. Local scouts were funded through grants provided by the UK Economic and Social Research Council, the Swiss Agency for Development and Cooperation's East and Southern African Partnership Programme (Grant no. E406), the US Fish and Wildlife Service (Grant no. 98210-4-G793), Save the Elephants, The Elephant Pepper Trust, The Symbiosis Trust and Safaricom Ltd. The UK Department of Food and Rural Affairs Darwin Initiative (Grant no. 15/040) funded the data analysis and reporting of this study. The Centre for Training and Research in ASAL Development and the Laikipia Wildlife Forum provided institutional and logistical support. Josephat Musyima and Loki Osborn provided technical advice. The Kenya Wildlife Service and community scouts provided field support. We are grateful to Bill Adams, Phyllis Lee, Iain DouglasHamilton and Boniface Kiteme for continued input and debate. 


\section{References}

Barnes, R.F.W. (1996) The conflict between humans and elephants in central African forests. Mammal Review, 26, 67-80.

Blanc, J.J., Thouless, C.R., Hart, J.A., Dublin, H.T., DouglasHamilton, I., Craig, G.C. \& Barnes, R.F.W. (2003) African Elephant Status Report 2002. Occasional Paper of the IUCN Species Survival Commission no. 29. IUCN/Species Survival Commission African Elephant Specialist Group, IUCN, Gland, Switzerland.

Bell, R.H.V. (1984) The man-animal interface: an assessment of crop-damage and wildlife control. In Conservation and Wildlife Management in Africa (eds R.H.V. Bell \& E. McShane-Caluzi), pp. 387-416. U.S. Peace Corps Office of Training and Program Support, Washington, DC, USA.

Graham, M.D. (2007) Coexistence in a land use mosaic? Land use, risk and elephant ecology in Laikipia District, Kenya. PhD thesis, University of Cambridge, Cambridge, UK.

Hill, C.M. (2000) A conflict of interest between people and baboons: crop raiding in Uganda. International Journal of Primatology, 21, 299-315.

Hill, C.M. (2004) Farmers' perspectives of conflict at the wildlife-agriculture boundary: some lessons learned from African subsistence farmers. Human Dimensions of Wildlife, 9, 279-286.

Hoare, R. (1995) Options for the control of elephants in conflict with people. Pachyderm, 19, 54-63.

Hoare, R. (1999) A Standard Data Collection and Analysis Protocol for Human-Elephant Conflict Situations in Africa. IUCN/Species Survival Commission African Elephant Specialist Group, Nairobi, Kenya.

Hoare, R. (2000) African elephants and humans in conflict: the outlook for coexistence. Oryx, 34, 34-38.

Hoare, R. (2001) Management implications of new research on problem elephants. Pachyderm, 30, 44-48.

Jenkins, P.R. \& Hamilton, P.H. (1982) The Laikipia Elephant Problem. Unpublished Report. Wildlife Conservation and Management Department, Ministry of Tourism and Wildlife, Nairobi, Kenya.

Lee, P. \& Graham, M.D. (2006) African elephants and humanelephant interactions: implications for conservation. International Zoo Yearbook, 40, 9-19.

Mwenge International Ltd (1979) Report on the Laikipia Elephant Drive. In Herbivores: A Study on the Management of Very Large Herbivores in Kenya. Vol II, Appendix III-1. Mwenge International Ltd, Nairobi, Kenya.

Naughton-Treves, L. (1997) Farming the forest edge: vulnerable places and people around Kibale National Park, Uganda. The Geographical Review, 87, 27-46.

Naughton-Treves, L. (1998) Predicting patterns of crop damage by wildlife around Kibale National Park, Uganda. Conservation Biology, 12, 156-168.

Naughton-Treves, L. (2001) Farmers, wildlife and the forest fringe. In African Rain Forest Ecology and Conservation (eds W. Weber, L. White, A. Vedder \& L. Naughton-Treves), pp. 369-384. Yale University Press, New Haven, USA.

Newmark, W.D., Manyanza, D., Gamassa, D.-G.M. \& Sariko, H.I. (1994) The conflict between wildlife and local people living adjacent to Protected Areas in Tanzania: human density as a predictor. Conservation Biology, 8, 249-255.

O'Connell-Rodwell, C.E., Rodwell, T., Rice, M. \& Hart, L.A. (2000) Living with the modern conservation paradigm: can agricultural communities co-exist with elephants? A five year case study in East Caprivi, Namibia. Biological Conservation, 93, 381-391.
Omondi, P., Bitok, E. \& Kagiri, J. (2004) Managing humanelephant conflicts: the Kenyan experience. Pachyderm, 36, 80-86.

Osborn, F.V. (1998) The ecology of crop-raiding elephants in Zimbabwe. PhD thesis, University of Cambridge, Cambridge, UK.

Osborn, F.V. \& Parker, G. (2002) Living with Elephants II: A Manual for Implementing an Integrated Programme to Reduce Crop Loss to Elephants and Improve Livelihood Security of SmallScale Farmers. Mid-Zambezi Elephant Project, Harare, Zimbabwe.

Osborn, F.V. \& Parker, G. (2003) Towards an integrated approach for reducing the conflict between elephants and people: a review of current research. Oryx, 37, 80-84.

Sitati, N.W. (2003) Human-elephant conflict in Transmara District adjacent to Masai Mara National Reserve. PhD thesis, University of Kent, Canterbury, UK.

Sitati, N.W. \& Walpole, M.J. (2006) Assessing farm-based measures for mitigating human-elephant conflict in Transmara District, Kenya. Oryx, 40, 279-286.

Smith, R.J. \& Kasiki, S.M. (2000) A Spatial Analysis of Humanelephant Conflict in the Tsavo Ecosystem, Kenya. IUCN/Species Survival Commission African Elephant Specialist Group, Human-Elephant Conflict Task Force, Gland, Switzerland.

Stephenson, P.J. (2004) The future for elephants in Africa. In Terrestrial Ecoregions of Africa and Madagascar: A Conservation Assessment (eds J.D.A.H. Burgess, N.E. Underwood, E. Dinerstein, D. Olson, I. Itoua, J. Schipper et al.), pp. 133-136. Island Press, Washington, DC, USA.

Tchamba, M. (1996) History and present status of the human/ elephant conflict in the Waza-Logone region, Cameroon, West Africa. Biological Conservation, 75, 35-41.

Thouless, C.R. (1993) Laikipia Elephant Project: Final Report. Unpublished Report to KWS and WWF Eastern African Regional Office. Kenya Wildlife Service, Nairobi, Kenya.

Thouless, C.R. (1994) Conflict between humans and elephants on private land in northern Kenya. Oryx, 28, 119-127.

Thouless, C.R. (1995) Long distance movements of elephants in northern Kenya. African Journal of Ecology, 33, 321-334.

Thouless, C.R. (1996) Home ranges and social organisation of female elephants in northern Kenya. African Journal of Ecology, 34, 284-297.

Thouless, C.R., Georgiadis, N. \& Olwero, N. (2002) A Wildlife Fencing Strategy for Laikipia. Unpublished Report. Laikipia Wildlife Forum, Nanyuki, Kenya.

Thouless, C. \& Sakwa, J. (1995) Shocking elephants: fences and crop raiders in Laikipia District, Kenya. Biological Conservation, 72, 99-107.

Wafula, J. (1998) Towards A Wildlife Fencing Master Plan for Laikipia District. Priority Areas of Human-Wildlife Conflict. Unpublished Report. Mpala Research Centre/ASAL Development Programme, Nanyuki, Kenya.

\section{Biographical sketches}

Max Graham has studied the relationship between wildlife ecology and human land use in Laikipia for 6 years and is currently coordinating a UK Darwin Initiative project for Cambridge University, UK, aiming to build capacity for alleviating human-elephant conflict in north Kenya and beyond. Tobias Ochieng has spent the last 2 years working with local farmers in Laikipia to monitor human-elephant conflict and trial farm-based elephant deterrents. 